\title{
Assessing the Effectiveness of Peer Instruction in Students' Understanding of Electric Circuits Concepts
}

\section{Mr. Rene Alexander Soto Perez, Purdue University, West Lafayette}

René Alexander Soto-Pérez received the B.S. and M.S. degrees in electrical engineering from the Universidad Nacional de Colombia, Bogota, Colombia, in 1997 and 2013, respectively. He is currently an Assistant Professor with the Department of Electrical and Electronics Engineering, Universidad Nacional de Colombia. He has experience in the field of electrical machines and distribution's systems. Currently, René is a Ph.D. student at Purdue University in the program of Engineering Education. His research interests include assessing students understanding of difficult concepts as well as the effectiveness of pedagogical approaches.

Mr. Juan David Ortega-Alvarez P.E., Purdue University, West Lafayette, and Universidad EAFIT, Colombia

Juan David Ortega Álvarez is an assistant professor at Universidad EAFIT (Medellin, Colombia). He holds a bachelor's degree in Process Engineering from EAFIT and an M.S. in Process Engineering and Energy Technology from Hochschule Bremerhaven (Germany). Juan David is currently a doctoral candidate of the Engineering Education Program at Purdue University. Before his full-time appointment with EAFIT, he served as the engineering director at a Colombian chemical company for seven years. His research interests are focused on the practice and instruction of process design, simulation, and automatic control, as well as on faculty and institutional development through the scholarship of teaching and learning and educational research.

\section{Dr. Ruth A. Streveler, Purdue University, West Lafayette}

Ruth A. Streveler is a Professor in the School of Engineering Education at Purdue University. Dr. Streveler has been the Principal Investigator or co-Principal Investigator of ten grants funded by the US National Science Foundation. She has published articles in the Journal of Engineering Education and the International Journal of Engineering Education and has contributed to the Cambridge Handbook of Engineering Education Research. She has presented workshops to over 500 engineering faculty on four continents. Dr. Streveler's primary research interests are investigating students' understanding of difficult concepts in engineering science and helping engineering faculty conduct rigorous research in engineering education. In 2015, Dr. Streveler was inducted as an ASEE Fellow. 


\title{
Assessing the effectiveness of Peer Instruction in students' understanding of electric circuits concepts
}

\begin{abstract}
This paper describes the implementation of an active learning strategy, called Peer Instruction, in an undergraduate electric circuit analysis course offered at a large public university in Colombia. Peer Instruction is an instructional approach that fosters students' collaboration to increase conceptual understanding. Data was collected from three sections of the course mentioned above. In two sections, students attended a traditional class format (51 students) while another section (15 students) implemented the Peer Instruction methodology. The research question driving this project was whether Peer Instruction would produce significantly higher learning gains than the traditional blackboard and chalk approach. A difference was determined using a quasi-experimental study comparing the learning gains of the students in the traditional sections (i.e., the control group) versus those of the students in the Peer Instruction section (i.e., the experimental group). The learning gains were measured by pre/post application of an adapted version of the DIRECT concept inventory which was translated into Spanish. Preliminary results suggest that the implementation of a Peer Instruction approach in an electric circuit analysis course improves the performance of students on the adapted version of the DIRECT test.
\end{abstract}

\section{INTRODUCTION}

Electric circuit analysis is a common topic in electrical engineering undergraduate programs worldwide. Although there is abundant educational literature on the adoption of innovative pedagogical strategies for teaching this topic, courses on electric circuits analysis are usually taught in a traditional class format. In this study, the authors describe the implementation of an active learning strategy, namely Peer Instruction (PI), in an electric circuit analysis course offered at a large public university in Colombia. Peer Instruction is an instructional approach that fosters students' collaboration to increase conceptual understanding. Students answer a conceptual question and then share their thoughts with a group of three to four classmates.

Data was collected from three sections of the course mentioned above. In two of the sections, students attended a traditional class format (51 students) while another section (15

students) implemented the Peer Instruction methodology. The research question driving this project was whether a Peer Instruction strategy would produce significantly higher learning gains than the traditional blackboard and chalk approach. A difference was determined using a quasi-experimental study comparing the learning gains of the students in the traditional sections (i.e., the control group) versus those of the students in the Peer Instruction section (i.e., the experimental group). The learning gains were measured by 
pre/post application of an adapted version of the DIRECT concept inventory. DIRECT is a validated test developed by Engelhardt and Beichner in 2004 at North Carolina State University, which focuses on basic concepts of DC circuits. One of the authors translated the DIRECT instrument into Spanish. The translated version of DIRECT was used to collect scores that served later on to determine the learning gains for each group and to compare them. Then, the authors verified the statistical significance of the difference between these gains.

\section{BACKGROUND}

\section{Peer Instruction}

For almost three decades, education researchers have advocated the adoption of teaching strategies that make students more active participants of their learning process [1]. Most of these strategies leverage interaction and collaboration between the students and have been proved to foster learning in engineering contexts [2], [3]. One of such strategies is Peer Instruction, a collaborative learning methodology implemented and documented by Eric Mazur [4] in physics education. According to Crouch and Mazur [5], "Peer Instruction modifies the traditional lecture format to include questions designed to engage students and uncover difficulties with the material." To implement Peer Instruction (PI), these researchers divided the content of a class session into multiple, short presentations of specific topics. After each presentation, students were asked to individually answer a conceptual question and report out on their answers. Then, the instructor encouraged students to convince their neighboring classmates of the correctness of their own answer and report out again. After listening to the multiple discussions and the variety of students' answers, the instructor proceeded to provide an explanation tailored to the particularities of the class and then moved on to the next topic. The time allocated for students to provide and discuss possible answers was usually no longer than six minutes, so the activity could be repeated multiple times during a session.

Crouch and Mazur [5] used standardized instruments, including the Force Concept Inventory [6], to determine the benefits of PI after almost a decade implementing this methodology. They found significant learning gains comparing the performance of students in the first course where PI was implemented with respect to the immediately previous course. Later, they compared two sections of the same course taught by different instructors, using PI in one section and a traditional approach in the second one. Despite both sections showed significant learning gains, the average scores of students in the PI section where significantly larger than those in the traditional one.

Most educational research on PI suggests that this pedagogical strategy is particularly effective to foster students' conceptual understanding [5], [7]. Faculty in the natural sciences are more likely to implement PI in higher education than engineering faculty. However, given its documented affordances, some instructors in different engineering 
fields have also implemented and assessed the impact of PI in their courses. For instance, Brooks and Koretsky [8] used a web-based interactive tool and clickers to implement PI in a chemical engineering thermodynamics class. Their results indicate that the benefits of PI hold as long as most students in a discussion group agree on the correct answer to begin with. Moreover, students in these groups can still increase their understanding and provide a better rationale as to why an answer is correct. On the other hand, students in groups that agreed on a wrong answer not only failed to increase their understanding, but some of them switched from the right to a wrong answer. The authors concluded that these results, somewhat contradictory to those of other studies [7], may be particular to the discipline being taught, namely undergraduate thermodynamics for chemical engineering in this case. From the perspective of the students, Kitch [9] compared the perceived effectiveness of Just in Time Teaching (JiTT) and PI to more traditional approaches in multiple undergraduate civil engineering courses. Results of this study suggest that while most students rated both JiTT and PI as effective or highly effective learning tools, the perceived effectiveness of traditional problem sets is significantly higher. Unfortunately, direct measurements of student performance are absent from this study.

Examples of the implementation and assessment of PI in basic electricity courses are scarce in scholarly literature. In Brazil, Araujo and colleagues implemented PI in seven high school physics classes, particularly around the topic of simple DC circuits [10]. These researchers pulled from the literature on concept inventories and local research on learning electric circuits to adapt and create the conceptual questions that informed both the operationalization of PI and the assessment strategy. Such strategy consisted of the application of a pre and post-test whose scores were normalized as Hake gains [11]. Unlike most studies, Araujo and colleagues did not compare student performance between a control, traditionally taught group and an experimental, PI group. Instead, they compared the normalized gains obtained with those found in scholarly literature. While most of these gains were lower than those reported in US literature, they were consistent with the local literature. Based on these findings, the researches posited that the implementation and evaluation of PI merits careful consideration of the factors relevant to a particular context.

\section{DIRECT Test}

A concept inventory is a standardized test to determine whether a learner has a working understanding of a set of concepts pertaining a specific domain. Concept inventories (CI) are used to inform and assess the impact of innovative pedagogical practices aimed at fostering conceptual understanding and conceptual change. It is not surprising, then, that the validity and reliability of concept inventories are subject of constant research. In fact, recent research has suggested that claims to validity of CI should be analyzed in light of evidence specific to the nature of the claims being made, beyond students' pre and post-test results [12]. 
Since its popularization in physics [6], most concept inventories have encompassed a set of multiple choice questions with one correct answer. The pool of incorrect answers usually includes common misconceptions as distractors. This description holds for the Determining and Interpreting Resistive Electric Circuit Concepts Test, commonly known as DIRECT [13]. Version 1.0 of DIRECT, which focuses on conceptual understanding, comprises a set of 29 questions on direct current (DC) resistive electrical circuits. These questions are qualitative in nature and designed to be applied at both high school and college level. To ensure reliability, the authors examined the item discrimination of these questions, with satisfactory results. Content validity was ensured by discussing and revising the questions with a panel of experts, while construct validity was examined through factor analysis.

Engelhardt and Beichner [13] confirmed that DIRECT was useful to identify misconceptions related to fundamental electrical concepts found in previous studies [14]. They also conducted individual follow-up interviews that revealed misconceptions persist after traditional instruction. Common misconception elicited included assigning to voltage and resistance the properties of current, believing that current is spent, and thinking of a battery as a source of constant current. Altogether, these results suggest that DIRECT seems to be a reliable and valid instrument to assess student conceptual understanding of DC electric circuits and elicit underlying difficulties and misconceptions.

\section{CONTEXT}

This section describes the context and settings of the study. First, it provides an overview of the course. Second, it details the settings and logistics for carrying this study. In addition, it describes how instruction was delivered to the control group. Finally, this section reports a description of the activities in the experimental group through PI.

The electric circuits course is offered by the Electrical and Electronics Engineering Department at the main campus of a large public university in Colombia. The population of this course is composed of students pursuing majors in electrical, electronics, and mechatronics engineering. The size of each section usually varies between 24 and 28 students. The topics covered in this course include DC circuits analysis, first and second order circuits' transient analysis, and monophasic AC circuits analysis.

During the fall of 2012, the lead author became interested in testing the PI approach to improve students' comprehension of fundamental concepts of electric circuits. The same semester, the lead author designed a quasi-experimental study for testing this hypothesis. Another instructor of this course agreed on using his two sections as a control group. Instead of using traditional instruction, the lead author implemented PI in his section, and it was used as the experimental group. The translated DIRECT test was applied to both groups before and after the topic of DC circuits analysis was covered. In the data collection stage, students were allowed 90 minutes to complete the DIRECT test using paper and 
pencil during a class session. Students' answers constitute the data set of interest for this study.

The control group consisted of two sections. These sections were taught by the same instructor. The pedagogy used by this instructor consisted of traditional lectures where he presented the topics, provided examples, asked questions, and assigned homework. Additionally, this instructor applied traditional pencil and paper exams with the purpose of both assessing students' learning and grading.

The experimental group consisted of one small section taught by lead author and employed only the Peer Instruction approach, which was implemented for each class session in three steps: 1) student preparation for the class session, 2) active discussion activities in the classroom, and 3) post-class assignments and homework.

In preparation for the class session, students were asked to read specific sections of the textbook. Then, they had to answer an online reading quiz very similar to the one described by Crouch and Mazur [5]. The deadline for students to answer the quiz was two hours before class started. This allowed the instructor to review what concepts students struggled with, and to prepare the class session to address those specific concepts.

During the class sessions, the instructor first posted conceptual questions with multiple answer options. Then, one or two minutes was allowed for students individually answered those questions using color cards to let the instructor know what option they chose.

Following, the instructor organized groups of three or four students where they were asked to discuss their rationale about the chosen option. The purpose of this discussion was to convince other students in the group to change their minds through academic argumentation. This was the core activity of the Peer Instruction approach [4], [5]. Next, students shared with the whole class their answers using the color cards, again. Finally, the instructor oriented a discussion with the whole class regarding the rationale of the right choice, and, sometimes, why the other choices were not correct. This process was repeated between two and six times every class session according to the number of difficult concepts for the students.

After the class session, students were required to do assignments and homework where they needed to use the concepts discussed in the classroom. Students were told to ask, in the following class session, any question regarding the concepts and topics covered in the assignment.

At the end of the experience, the instructor applied a simple perception survey to the students in the experimental group. In this survey, students reported a perceived high usefulness of the Peer Instruction activities. Specifically, they mentioned that the activities helped them to understand the concepts discussed. 
Regarding instructor time to produce new course materials, the first semester PI was implemented the lead author invested around twice the time for preparing for a PI session compared to the required time for preparing for a traditional lecture. The following semesters, the required time for preparing a session with PI got closer to the required time to prepare a traditional lecture. Presently, the instructor can better manage his class preparation time because the PI materials developed in the first semesters have been reused. Moreover, this material has been shared with other faculty members in several engineering schools around Colombia.

\section{METHODS AND RESULTS}

\section{Methods}

Data for the present study came from the repeated administration of the translated DIRECT test. Students in both the control and experimental groups took the test before and after the teaching intervention, which resulted in four data subsets: Experimental group pretest (EGPre); experimental group post-test (EG-Post); control group pretest (CG-Pre); and control group post-test (CG-Post).

During the first round of data analysis, the authors used the entire data set comprising students' answers to the 29 translated questions. Comparisons over this entire data set did not yield statistically significant difference in the post-test performance between the control and the experimental group. This result contrasted with the positive perception of students and instructor alike. For that reason, the authors decided to try a second approach to the data analysis by removing carefully selected questions.

DIRECT has 29 question items, and the lead author-who also was the instructor of the experimental group - identified three groups of questions were aimed at assessing concepts not addressed in this particular course. Specifically, these concepts are "microscopic aspects of current flow in a circuit (questions 1, 11, and 20); "interpret pictures and diagrams of a variety of circuits" (questions 4, 13, and 22); and "apply the concept of resistance including that resistance is a property of the object" (questions 5, 14, and 23). These nine items were removed from analysis and therefore, while students responded to all 29 questions, the present study draws from the relevant 20 questions. Students' responses to each question in the test were assigned a score of either one (1) if the response matched the correct choice, or zero (0) otherwise. There was no partial credit since DIRECT is a multiple-choice test with only one right answer. A final score for each student was then calculated simply as the sum of the question scores (i.e., the number of correct responses), for a maximum student score of 20 .

The following subsection presents the descriptive statistics for the four data subsets, followed by an inferential analysis to test the significance of the differences between relevant pairs of subsets. Given the small sample size and the non-normality of the data, non-parametric statistical tests were used to run the inferential analysis, namely the 
Wilcoxon rank sum test for the difference between independent groups, and the asymptotic Wilcoxon-Pratt signed-rank test for the paired (pre- and post-test) observations. In addition, a rank correlation [15] was used to estimate non-parametric effect sizes when appropriate.

\section{Descriptive and Inferential Statistics}

Table 1 presents the descriptive statistics for the four data subsets. It is worth noting that, for both the experimental and control groups, only around $60 \%$ of the students who took the pretest also took the post-test. Data on the table for the post-test corresponds to students who took both the pre and post-test. IQR stands for interquartile range.

Table 1. Descriptive statistics for the adapted version of DIRECT (20 questions)

\begin{tabular}{|c|c|c|c|c|c|c|c|}
\hline Subset & $\boldsymbol{N}$ & Median & \multicolumn{1}{c}{ Q1 } & Q3 & IQR & Min & Max \\
\hline EG-Pre & 15 & 10 & 8.5 & 12 & 3.5 & 6 & 16 \\
\hline EG-Post & 10 & 15.5 & 14 & 18 & 4 & 12 & 19 \\
\hline CG-Pre & 51 & 11 & 8 & 13.5 & 5.5 & 3 & 20 \\
\hline CG-Post & 30 & 11 & 9 & 15.75 & 6.75 & 5 & 20 \\
\hline
\end{tabular}

Since the groups in the study were not randomly formed, it was important to test whether the experimental and control groups started at a comparable point. Testing the difference between the pretest scores (i.e., EG-Pre and CG-Pre) showed no significant difference ( $W=$ $421, p=0.5591)$. In other words, the experimental and control groups arguably performed equally in the DIRECT test at the beginning of the course.

Secondly, it was of interest to test the difference between the pre- and post-test performance within each group, to assess the impact of the pedagogical intervention in fostering learning. Application of the paired Wilcoxon-Pratt test suggested that both the control $(Z=-3.76, p<0.001, n=30)$ and the experimental $(Z=-2.7575, p=0.0029, n=$ 10) showed a significant increase in their DIRECT scores after the pedagogical intervention. Estimation of the effect size using a rank correlation [16, p. 225] yielded 0.49 for the control group and 0.62 for the experimental group.

While both size effects are moderate to high, the larger size effect of the experimental group suggested a potential difference between the performance of the two groups after the pedagogical intervention. This difference between the post-test scores in the adapted DIRECT test of both groups (i.e., EG-Post and CG-post) was tested again for statistical significance. Results suggest that the post-test scores of the experimental group were statistically significantly higher than those of the control group $(W=71.5, p=0.0146)$. 


\section{CONCLUSION}

At its heart, this study is about pedagogy and the use of Peer Instruction to improve student learning. The results of the study add to the large body of literature that demonstrates that interactive learning activities improve learning gains [17] and broaden the evidence-base by focusing on a South American student population. Even though this project started as the application of Peer Instruction to one course, there are wider benefits to the academic community by evaluating Peer Instruction in a South American electrical engineering context.

However, this work also highlights the importance of being deliberate about how learning is assessed. As we saw here, the entire set of questions in an existing inventory might not be appropriate for a particular population. When examining the DIRECT inventory, the lead author realized that a large percentage of the 29 questions were not relevant for his students. Either the questions were probing concepts not addressed in the class, or they were too basic for his audience - as shown by pretest results. When questions addressing those concepts were removed, a more accurate measure of learning was created. Being mindful of the structure of the inventory, all questions that the original inventory designers had shown clustered around a particular concept were removed. The point here is that although altering an established inventory may be called for, there needs to be a solid rationale for the alterations, and the process of removing questions need to be done in a systematic way.

Limitations of this project include the small size of the sample, particularly when accounting for the number of students who participated in both the pre and post-tests, and the difference in the sizes between the two groups. The use of a translated, non-validated version of DIRECT also must be noted as a limitation of the present study. On the other hand, this limitation offers the possibility to work in the validation of a translated, adapted version of the DIRECT concept inventory. In the same vein, possibilities for future work include assessing the impact that context variables can have on the effectiveness of Peer Instruction and its implementation in different settings, as well as evaluating the pros and cons in instructors' workload, and possibilities for conducting classrooms research. 


\section{References}

[1] D. W. Johnson, R. T. Johnson, and K. A. Smith, Active learning: Cooperation in the college classroom. Interaction Book Company, 1991.

[2] M. Prince, "Does active learning work? A review of the research," J. Eng. Educ., vol. 93, pp. 223-231, 2004.

[3] K. A. Smith, S. D. Sheppard, D. W. Johnson, and R. T. Johnson, "Pedagogies of engagement: Classroom-based practices," J. Eng. Educ., vol. 94, no. 1, pp. 87-101, 2005.

[4] E. Mazur, Peer instruction: A user's manual. Upper Saddle River, NJ: Prentice Hall, 1997.

[5] C. H. Crouch and E. Mazur, "Peer instruction : Ten years of experience and results," Am. J. Phys., vol. 69, pp. 970-977, 2001.

[6] D. Hestenes, M. Wells, and G. Swackhamer, "Force concept inventory," Phys. Teach., vol. 30, pp. 141-158, 1992.

[7] M. K. Smith et al., "Why peer discussion improves student performance on in-class concept questions.," Science (80-. )., vol. 323, pp. 122-124, 2009.

[8] B. Brooks and M. Koretsky, "The effect of Peer Instruction on students' construction of conceptual understanding in thermodynamics," in ASEE Annual Conference and Exposition, 2010.

[9] W. A. Kitch, "Evaluation of effectiveness of Just-in-Time Teaching and Peer Instruction methods in civil engineering courses.," J. Eng. Educ., pp. 01112-01111, 2011.

[10] A. V. R. de Araujo, E. S. Silva, V. L. B. de Jesus, and A. L. de Oliverira, "Uma associaçâo do método Peer Instruction com circuitos elétricos em contextos de aprendizagem ativa," Rev. Bras. Ensino Física, vol. 39, no. 2, pp. 2401-1-2401-6, 2017.

[11] R. R. Hake, "Interactive-engagement versus traditional methods: A six-thousandstudent survey of mechanics test data for introductory physics courses," Am. J. Phys., vol. 66, no. 1, pp. 64-74, 1998.

[12] N. Jorion, B. D. Gane, K. James, L. Schroeder, L. V. DiBello, and J. W. Pellegrino, "An analytic framework for evaluating the validity of concept inventory claims," $J$. Eng. Educ., vol. 104, no. 4, pp. 454-496, 2015.

[13] P. V. Engelhardt and R. J. Beichner, "Students' understanding of direct current resistive electrical circuits," Am. J. Phys., vol. 72, no. 1, pp. 98-115, 2004.

[14] L. C. McDermott and P. S. Shaffer, "Research as a guide for curriculum development: An example from introductory electricity. Part I: Investigation of student understanding," Am. J. Phys., vol. 60, no. 11, pp. 994-1003, 1992.

[15] E. E. Cureton, "Rank-biserial correlation," Psychometrika, vol. 21, no. 3, pp. 287290, Sep. 1956.

[16] J. Pallant, SPSS Survival Manual: A Step by Step Guide to Data Analysis Using IBM SPSS, 3rd ed. Maidenhead, Berkshire: Open Univ Press, 2007.

[17] M. T. H. Chi, "Active-Constructive-Interactive : A conceptual framework for differentiating learning activities," Top. Cogn. Sci., vol. 1, pp. 73-105, 2009. 